\title{
Controle da hiperfosfatemia na DRC
}

\author{
Management of hyperphosphatemia in CKD
}

\section{Autores:}

Aluizio Barbosa de Carvalho Lilian Cuppari
1 Avaliação dos níveis de fósforo sérico na DRC

1.1 O fósforo $(\mathrm{P})$ sérico deve ser dosado em todos os pacientes com doença renal crônica (DRC), a partir do estágio III, ou seja, quando a taxa de filtração glomerular (TFG) for inferior a $60 \mathrm{~mL} / \mathrm{min} / 1,73 \mathrm{~m}^{2}$. A Tabela 1 descreve as frequências e os valores recomendados para cada estágio da DRC (Evidência).

1.2 A coleta de sangue para avaliação do $\mathrm{P}$ sérico deverá ser preferencialmente em jejum (Opinião).

2 Avaliação da ingestão e prescrição dietética de P na DRC

2.1 A avaliação da ingestão dietética de $\mathrm{P}$ e a prescrição de $\mathrm{P}$ dietético deverão ser sempre realizadas por nutricionista (Opinião).

2.2 Na DRC estágios III e IV, a ingestão dietética de $\mathrm{P}$ deverá ser mantida em valores que atendam a recomendação de proteínas entre 0,6 e $0,8 \mathrm{~g} / \mathrm{kg} / \mathrm{dia}$, porém não superior a $700 \mathrm{mg} / \mathrm{dia}$ se o $\mathrm{P}$ estiver acima dos valores normais e/ou se o paratormônio (PTH) estiver acima do nível recomendado para o estágio da DRC (Opinião).
2.3 Na DRC estágio V D, a ingestão dietética de $\mathrm{P}$ deverá estar entre 800 e $1.000 \mathrm{mg} / \mathrm{dia}$, respeitando a recomendação de pelo menos 1,0 g de proteína $/ \mathrm{kg} / \mathrm{dia}(50 \%$ de proteína de alto valor biológico), desde que o P sérico não esteja abaixo de 3,5 mg/dL (Opinião).

2.4 Alimentos que contêm aditivos à base de $\mathrm{P}$ devem ser restringidos ao máximo (Evidência).

2.5 Alimentos com menor razão P/ proteína devem ser preferencialmente empregados (Evidência).

\section{Uso de quelantes de P na DRC}

3.1 Os quelantes de P deverão ser tomados no mesmo momento em que alimentos que contenham quantidade significativa de $\mathrm{P}$ são ingeridos. A dose prescrita deverá estar de acordo com a quantidade de $\mathrm{P}$ contida na refeição estimada por meio de inquérito dietético (Opinião).

Pacientes com DRC estágios III-V

3.2 Os quelantes de $\mathrm{P}$ devem ser prescritos se, apesar do controle da ingestão dietética, o P sérico e/ou o PTH estiverem acima dos níveis recomendados (Opinião).

\begin{tabular}{|c|c|c|c|}
\hline Tabela 1 & $\begin{array}{l}\text { VALORES RECOMENI } \\
\text { DIFERENTES ESTÁGIC }\end{array}$ & $\begin{array}{l}\text { DOS E FREQUÊNCIA DE AVALIAÇÃO } \\
\text { DA DRC }\end{array}$ & NÍVEIS DE P NOS \\
\hline Estágio da DRC & TFG $(\mathrm{mL} / \mathrm{min})$ & Níveis de $P$ (mg/dL) & $\begin{array}{l}\text { Frequência de } \\
\text { dosagem }\end{array}$ \\
\hline III & $30-59$ & Dentro do valor de referência & Semestral/anual \\
\hline IV & $15-29$ & Dentro do valor de referência & Semestral/trimestral \\
\hline V & $<15$ & Dentro do valor de referência & Trimestral/mensal \\
\hline VD & Diálise & $\begin{array}{c}\text { Reduzir o P sérico em direção } \\
\text { ao valor normal }\end{array}$ & Mensal \\
\hline
\end{tabular}


3.2.1 Quelantes de P à base de cálcio $(\mathrm{Ca})$ são efetivos e podem ser utilizados desde que a dose total de $\mathrm{Ca}$ elemento neles contida não exceda $1,5 \mathrm{~g} / \mathrm{dia}$ ou, incluindo o $\mathrm{Ca}$ da dieta, não exceda 2,0 g/dia. Além disso, quelantes à base de Ca não devem ser utilizados na presença de hipercalcemia persistente e recorrente, ou então, na presença de calcificação vascular, doença óssea adinâmica ou níveis de PTH persistentemente baixos. Dentre os quelantes à base de $\mathrm{Ca}$, o acetato de $\mathrm{Ca}$ deve ser utilizado preferencialmente (Opinião).

3.2.2 Quelantes de P isentos de Ca (carbonato de sevelamer e carbonato de lantânio) são efetivos e podem ser utilizados; devem ser a primeira escolha nos casos em que haja contraindicação ao uso de quelantes à base de $\mathrm{Ca}$ (Opinião).

\section{Pacientes com DRC estágio V D}

3.3 Tanto os quelantes de $\mathrm{P}$ à base de $\mathrm{Ca}$, assim como aqueles isentos de $\mathrm{Ca}$ (carbonato ou cloridrato de sevelamer e carbonato de lantânio), são efetivos e ambos podem ser utilizados como terapia inicial (Evidência).

3.3.1 A dose total de Ca elemento fornecida pelos quelantes de $\mathrm{P}$ à base de $\mathrm{Ca}$ não deve exceder 1,5 g/dia ou, incluindo o Ca da dieta, não exceder 2,0 g/dia (Opinião).

3.3.2 Quelantes de $\mathrm{P}$ à base de Ca não devem ser utilizados na presença de hipercalcemia persistente e recorrente, ou na presença de calcificação vascular, doença óssea adinâmica ou níveis de PTH persistentemente baixos (Opinião).

3.3.3 Quelantes de P à base de alumínio não deverão ser utilizados em qualquer circunstância (Evidência).

\section{Dose de diálise}

4.1 Em pacientes em diálise, nos quais as medidas dietéticas e terapêuticas não foram suficientes para o controle adequado do P sérico, a dose de diálise deverá ser aumentada (Opinião).

4.1.1 Para pacientes em hemodiálise (HD), uma sessão extra de 2 horas é preferível em vez do aumento das horas de diálise de uma sessão-padrão (Opinião).

\section{RACIONAL}

A hiperfosfatemia na DRC é resultante de três fatores principais: a ingestão excessiva de $\mathrm{P}$, a redução da depuração de $\mathrm{P}$ (renal e pelos métodos dialíticos) e o estado da remodelação óssea (alta ou baixa).

A retenção de $\mathrm{P}$ e/ou a hiperfosfatemia estão entre os fatores que contribuem para o desenvolvimento do hiperparatireoidismo secundário (HPS) em pacientes com DRC. A hiperfosfatemia também está associada com morbidade e mortalidade nesses pacientes, principalmente relacionadas aos eventos cardiovasculares. ${ }^{1,2}$ Os mecanismos pelos quais a retenção de P aumenta o risco de eventos cardiovasculares e de mortalidade ainda não estão totalmente elucidados. ${ }^{3,4}$ Esses mecanismos envolvem a transformação fenotípica das células musculares lisas da camada média dos vasos arteriais, induzidas pelo $\mathrm{P}$ ou indiretamente pelos efeitos da hiperfosfatemia sobre o PTH, desencadeando o HPS e a calcificação vascular. ${ }^{5,6}$

$\mathrm{O}$ racional para prevenir a retenção de $\mathrm{P}$ ou tratar a hiperfosfatemia estabelecida está no seu conhecido papel no desenvolvimento do HPS. Além disso, outros benefícios ainda não provados seriam a diminuição do risco de calcificação vascular e de tecidos moles, prevenção de eventos cardiovasculares e de progressão da DRC. As evidências disponíveis suportam que valores de $\mathrm{P}$ séricos, inferiores ou superiores aos da faixa de normalidade, se associam com piores desfechos incluindo morte. ${ }^{2,7}$ Porém, os níveis recomendados de $\mathrm{P}$, associados com melhor prognóstico, são difíceis de determinar.

Nos estágios II, III e IV da DRC, os estudos que avaliam esse aspecto são escassos. Recentemente, foi reportado que níveis de $\mathrm{P}$ sérico acima de $3,5 \mathrm{mg} / \mathrm{dL}$, em pacientes na fase pré-dialítica, estavam associados com aumento da mortalidade. ${ }^{8}$ No estágio V D da DRC, os achados de estudos observacionais indicam diferentes valores associados com risco de complicações cardiovasculares ou morte. Porém, uma análise recente de uma coorte de 40.000 pacientes prevalentes em HD demonstrou que o risco de morte aumenta quando o P plasmático se encontra acima de 5,0 mg/ $\mathrm{dL}{ }^{2}$ Assim, as evidências sugerem que níveis de P sérico dentro da faixa de normalidade estão associados com melhores desfechos. No entanto, ainda há necessidade de estudos de intervenção que possam identificar com maior precisão os níveis ideais de $\mathrm{P}$ para os pacientes com DRC.

Estudos mostram que a concentração sérica de $\mathrm{P}$ se mantém dentro da faixa de normalidade até que a TFG decline para 20 a $30 \mathrm{~mL} / \mathrm{min}^{8}{ }^{8}$ 
Isso faz supor que a intervenção dietética com relação ao P só é necessária quando o P se encontra acima dos valores normais. No entanto, a retenção de P parece ocorrer precocemente no curso da DRC, participando, assim, da gênese do HPS. Porém, não existem estudos, até o momento, que identifiquem o valor de $\mathrm{P}$ sérico a partir do qual o controle da sua ingestão deva ser iniciado. Assim, foi consenso desse grupo de trabalho que a ingestão de $\mathrm{P}$ nos estágios III e IV da DRC não exceda $700 \mathrm{mg} / \mathrm{dia}$, que é o valor recomendado para indivíduos adultos saudáveis de acordo com as Recommended Dietary Allowances (RDA). ${ }^{9} \mathrm{O}$ controle deve ser feito particularmente para aqueles pacientes com $\mathrm{P}$ sérico acima do normal ou ainda para aqueles com níveis de PTH acima dos valores recomendados, mesmo que o $\mathrm{P}$ sérico esteja normal. $\mathrm{O}$ controle da ingestão de $\mathrm{P}$ deve ser feito com cuidado, de forma a não provocar redução excessiva da sua concentração sérica, visto que a hipofosfatemia pode indicar ingestão insuficiente de proteína, além de estar associada ao maior risco de morbimortalidade. ${ }^{7}$

No estágio V da DRC, a redução na ingestão de P é necessária, já que os métodos dialíticos são relativamente ineficientes na sua remoção. Porém, um fator limitante é a manutenção da elevada necessidade de proteína (1,0 a 1,2 g/kg/dia) nesse estágio da
DRC. Os alimentos com alto teor de proteína são naturalmente ricos em $\mathrm{P}$ e contribuem com a maior parte do $\mathrm{P}$ ingerido. Assim, é muito difícil atender à necessidade de proteína com uma oferta de $\mathrm{P}$ inferior a $800 \mathrm{mg} / \mathrm{dia}$.

De qualquer forma, ações devem ser implementadas de maneira a evitar que a ingestão de $\mathrm{P}$ seja superior a $1.000 \mathrm{mg} /$ dia. Na Tabela 2, estão apresentados os alimentos fontes de proteína e P. Uma forma de oferecer a quantidade necessária de proteína, com o menor teor possível de $\mathrm{P}$, é selecionar os alimentos que têm a menor relação P/proteína, conforme mostrado na Tabela 2. Estudo recente com pacientes em hemodiálise demonstrou pela primeira vez que o risco de morte foi 2,37 vezes maior no maior tercil de ingestão de P quando comparado ao menor tercil. Além disso, o risco também foi maior no grupo de pacientes com relação P/proteína da dieta acima de $16 \mathrm{mg} / \mathrm{g} .{ }^{10}$ Além disso, é importante a restrição de alimentos processados que contêm aditivos à base de $\mathrm{P}$ (ácido fosfórico, polifosfatos e pirofosfatos) como alimentos semiprontos, os chamados fast foods, embutidos, queijos processados, produtos instantâneos, biscoitos, cereais matinais e refrigerantes à base de cola. Há evidência que a restrição de alimentos que contêm aditivos de $\mathrm{P}$ promove redução na fosfatemia em pacientes em HD. ${ }^{11}$

\section{Tabela 2 PRINCIPAIS ALIMENTOS FONTES DE FÓSFORO E DE PROTEINA}

\begin{tabular}{lccccc} 
Alimento & Quantidade $(\mathrm{g})$ & Medida caseira & $\mathrm{P}(\mathrm{mg})$ & Proteína $(\mathrm{g})$ & $\begin{array}{c}\text { Relação } \\
\text { P/Proteína }(\mathrm{mg} / \mathrm{g})\end{array}$ \\
\hline Carne de frango & 80 & 1 filé de peito médio & 150 & 23,0 & 6,5 \\
Carne de porco & 80 & 1 bisteca média & 147 & 21,2 & 6,9 \\
Carne bovina & 85 & 1 bife médio & 209 & 26,0 & 8,0 \\
Pescada branca & 84 & 1 filé médio & 241 & 20,6 & 11,7 \\
Ovo inteiro & 50 & 1 unidade & 90 & 6,0 & 15 \\
Clara de ovo & 30 & 1 unidade & 4,3 & 3,3 & 1,3 \\
Fígado de boi & 85 & 1 bife médio & 404 & 22,7 & 17,8 \\
Sardinha & 34 & 1 unidade & 170 & 8,4 & 20,2 \\
Presunto & 48 & 2 fatias médias & 136 & 14 & 9,7 \\
Queijo prato & 30 & 2 fatias finas & 153 & 7,5 & 20,4 \\
logurte & 120 & 1 pote pequeno & 159 & 6,3 & 25,2 \\
Leite & 150 & 1 copo americano & 140 & 4,9 & 28,6 \\
Soja cozida & 54 & 5 colheres de sopa & 130 & 9 & 14,5 \\
Feijão cozido & 154 & 1 concha média & 133 & 6,9 & 19,3 \\
Amendoim & 50 & 1 pacote pequeno & 253 & 13 & 19,5 \\
Chocolate & 40 & 1 barra pequena & 92 & 3 & 30,7 \\
\hline
\end{tabular}


Uma orientação dietética individualizada por nutricionistas, associada a programas de educação nutricional, é fundamental para melhorar a adesão do paciente. $^{12}$

Considerando-se as limitações associadas com a restrição de $\mathrm{P}$ e com a remoção de $\mathrm{P}$ pela diálise, os quelantes de $\mathrm{P}$ são necessários para quase todos os pacientes submetidos à diálise. Em teoria, os quelantes de $\mathrm{P}$ deveriam prevenir ou tratar a hiperfosfatemia. No entanto, na prática clínica observa-se que o efeito dos quelantes é limitado. Os principais quelantes de $\mathrm{P}$ utilizados em nosso meio, bem como suas características, estão listados na Tabela 3.

A escolha do tipo de quelante e a dose a ser prescrita dependerão de alguns fatores. Primeiramente, nas refeições em que a quantidade de $\mathrm{P}$ é maior, o quelante deve ser prescrito em maior quantidade e, naquelas refeições em que não há alimentos ricos em $\mathrm{P}$, não há necessidade de quelante. Lanches ou alimentos com elevada quantidade de $\mathrm{P}$, ingeridos a qualquer momento, devem ser sempre associados com os quelantes. Não existem doses estabelecidas para a prescrição de quelantes baseadas na quantidade de $\mathrm{P}$ da alimentação.

Dessa forma, o acompanhamento frequente é a melhor maneira de avaliar a adequação da prescrição, fazendo ajustes quando necessário. Os quelantes devem ser ingeridos junto com a alimentação, de forma a permitir a melhor mistura com os alimentos. É importante que o paciente compreenda como agem os quelantes, para que se obtenha a melhor adesão e, consequentemente, os melhores resultados. Outra consideração a ser feita é quanto aos níveis de $\mathrm{Ca}$ séricos. Pacientes com hipercalcemia não devem utilizar quelantes que contêm $\mathrm{Ca}$, e para aqueles com calcemia no limite superior da normalidade a dose prescrita de quelantes à base de $\mathrm{Ca}$ deve ser bastante cautelosa. Se essa for a única opção, usar acetato de $\mathrm{Ca}$. A dose de $\mathrm{Ca}$ elementar proveniente de quelantes não deve exceder a $1.500 \mathrm{mg} / \mathrm{dia} .{ }^{14}$
Caso haja contraindicação ao uso de quelantes à base de $\mathrm{Ca}$, o cloridrato de sevelamer deve ser sempre empregado. Uma atenção deve ser dada àqueles pacientes em uso de 1,25-hidroxivitamina D (calcitriol), já que esse hormônio promove aumento na absorção intestinal de $\mathrm{Ca}$ e de $\mathrm{P}$. A observação e o acompanhamento dos níveis de PTH ao longo do tratamento também são necessários, pois muitas vezes o HPS se mostra resistente ao tratamento clínico, situação esta que inviabiliza a diminuição do $\mathrm{P}$ sérico, mesmo com a restrição dietética e utilização maciça de quelantes. Além disso, na situação oposta, ou seja, no hipoparatireoidismo relativo, quando a remodelação óssea está diminuída, a reduzida incorporação de $\mathrm{P}$ pelo osso faz com que a hiperfosfatemia se mantenha. Nesses dois casos, outras opções de tratamento devem ser consideradas, sendo importante que o paciente seja informado quanto às razões da falha no tratamento. A avaliação do tratamento proposto deve acontecer periodicamente, para que ajustes dietéticos e medicamentosos possam ser realizados. Finalmente, o sucesso da terapia depende fundamentalmente da participação do paciente. Assim, as orientações devem ser claras e objetivas e toda a equipe multiprofissional deve estar envolvida e, em especial, o nutricionista.

Quando o controle dietético e o uso de quelantes de P são insuficientes, mudanças na prescrição de diálise podem ser medidas coadjuvantes. $\mathrm{O}$ tratamento dialítico convencional é insuficiente para manter um balanço negativo de $\mathrm{P}$ na maioria dos pacientes em diálise. Tal fato torna-se óbvio quando comparamos a capacidade de depuração de $\mathrm{P}$ de uma sessão de 4 horas de HD, que é de aproximadamente $900 \mathrm{mg}$ de $\mathrm{P},{ }^{15}$ com a quantidade diária ingerida, que é de até $1.000 \mathrm{mg} /$ dia, contida em uma dieta preconizada com 1,0 a $1,2 \mathrm{~g}$ de proteína $/ \mathrm{kg} / \mathrm{dia} .{ }^{14}$ Mesmo alterações na composição e fluxo do dialisato, assim como no tipo de membrana capilar, não se mostram efetivas na melhora da depuração de P. ${ }^{16,17}$

Tabela 3 PRINCIPAIS QUELANTES DE FÓSFORO COM SUAS RESPECTIVAS CARACTERÍSTICAS

\begin{tabular}{lccl} 
Quelante & Poder quelante & Vantagens & \multicolumn{1}{c}{ Efeitos adversos } \\
\hline $\begin{array}{l}\text { Carbonato de cálcio } \\
\text { (40\% de cálcio elementar) }\end{array}$ & Baixo & Baixo custo & $\begin{array}{l}\text { - Constipação } \\
\text { Acetato de cálcio }\end{array}$ \\
$\begin{array}{l}\text { (25\% de cálcio elementar) } \\
\text { Cloridrato de Sevelamer }\end{array}$ & Moderado & $\begin{array}{c}\text { Maior poder quelante } \\
\text { com menor oferta de } \\
\text { cálcio que o carbonato } \\
\text { de cálcio }\end{array}$ & $\begin{array}{l}\text { - Constipação e nálaseas } \\
\text { - Hipercalcemia e calcificação metastática }\end{array}$ \\
& Moderado & $\begin{array}{c}\text { Não contém alumínio } \\
\text { ou cálcio }\end{array}$ & $\begin{array}{l}\text { - Diarreia ou constipação, flatulência, náuseas } \\
\text { e dispepsia }\end{array}$ \\
\hline
\end{tabular}


Já a diálise peritoneal (DP) é capaz de prover um controle do $\mathrm{P}$ pouco melhor que a $\mathrm{HD}$, porém ainda insuficiente. ${ }^{18}$

A remoção inadequada do $\mathrm{P}$ pela $\mathrm{HD}$ convencional decorre de sua própria cinética. Primeiramente, é fundamental sabermos que o P é um elemento predominantemente intracelular. Durante a primeira hora de uma sessão de HD ocorre uma rápida remoção de $\mathrm{P}$, que atinge o seu pico por volta dos 120 minutos. A partir daí, a taxa de remoção cai e se mantém em torno da metade daquela da fase inicial, sem que haja, porém, alteração do $\mathrm{P}$ sérico. ${ }^{15}$ Finalmente, pode haver um rebote pós-dialítico no qual os níveis de $\mathrm{P}$ podem até mesmo exceder os do início da sessão de diálise. . $^{15,19}$

Portanto, a cinética da remoção do $\mathrm{P}$ obedece a um modelo de duas fases. Inicialmente, ocorre a remoção do P do compartimento extracelular, seguida por um fluxo de P do meio intra para o extracelular, o que mantém seu nível sérico constante ao longo do restante do tratamento. São justamente a velocidade de efluxo de P para o dialisato durante as primeiras horas de diálise e a velocidade de mobilização entre os compartimentos intra e extracelular que limitam a remoção do P. Daí, a frequência e a duração das sessões de diálise correlacionam-se diretamente com o controle adequado da fosfatemia.

Os efeitos de novos padrões de HD, como a diária e a prolongada noturna, sobre o controle do $\mathrm{P}$ têm sido estudados. ${ }^{20-23} \mathrm{Um}$ achado universal desses estudos é o melhor controle do $\mathrm{P}$, com redução ou mesmo interrupção do uso de quelantes de P. Além disso, obtém-se melhor controle do PTH e do produto $\mathrm{Ca} \times \mathrm{P} .{ }^{23,24}$ Embora promissoras, essas modalidades dialíticas ainda não fazem parte da nossa prática diária. Nos casos de hiperfosfatemia grave, podemos sempre lançar mão do aumento no número de sessões semanais de diálise ou de sua duração, embora, por vezes, haja resistência por parte do paciente, em razão da interferência direta em seu cotidiano. Além disso, uma vez que a HD convencional é um método limitado para o controle do P, são de extrema importância a assiduidade do paciente e a manutenção da adequação de diálise, evitando-se a redução do tempo de tratamento, prática que vem tornandose frequente em nosso meio.

\section{ReferênCIAS}

1. London GM, Guerin AP, Marchais SJ et al. Arterial media calcification in end-stage renal disease: impact on all-cause and cardiovascular mortality. Nephrol Dial Transplant. 2003; 18:1731-40.
2. Block GA, Klassen PS, Lazarus JM et al. Mineral metabolism, mortality, and morbidity in maintenance hemodialysis. J Am Soc Nephrol. 2004; 15:2208-18.

3. Giachelli CM. Vascular calcification mechanisms. J Am Soc Nephrol. 2004; 15:2959-64.

4. Kavanaugh MP, Kabat D. Identification and characterization of a widely expressed phosphate transporter/retrovirus receptor family. Kidney Int. 1996; 49:959-63.

5. Almaden Y, Hernandez A, Torregrosa V et al. High phosphate level directly stimulates parathyroid hormone secretion and synthesis by human parathyroid tissue in vitro. J Am Soc Nephrol. 1998; 9:1845-52.

6. Goodman WG, Goldin J, Kuizon BD et al. Coronaryartery calcification in young adults with end-stage renal disease who are undergoing dialysis. N Engl J Med. 2000; 342:1478-83.

7. Lowrie EG, Lew NL. Death risk in hemodialysis patients: the predictive value of commonly measured variables and an evaluation of death rate differences between facilities. Am J Kidney Dis. 1990; 15:458-82.

8. Kestenbaum B, Sampson JN, Rudser KD et al. Serum phosphate levels and mortality risk among people with chronic kidney disease. J Am Soc Nephrol. 2005; 16:520-8.

9. Institute of Medicine/Food and Nutrition Board: Dietary reference intakes for calcium, phosphorus, magnesium, vitamin D and fluoride. Washington, National Academy Press, 1997. 432p.

10. Noori N, Kalantar-Zadeh K, Kovesdy CP et al. Association of dietary phosphorus intake and phosphorus to protein ratio with mortality in hemodialysis patients. Clin J Am Soc Nephrol. 2010; 5:683.

11. Sullivan C, Sayre SS, Leon JB et al. Effect of food additives on hyperphosphatemia among patients with endstage renal disease. JAMA 2009; 301:629.

12. Nisio MJ BA, Kamimura MA, Lopes MGG et al. Impacto de um programa de educação nutricional no controle da hiperfosfatemia de pacientes em hemodiálise. J Bras Nefrol. 2007; 29:152-7.

13. United States of America (USA). Human Nutrition Information Service. Department of Agriculture: Composition of foods: Raw, processed, prepared foods. Agriculture Handbook n.8, series 1-16. Revised 1976-1986.

14. National Kidney Foundation (NKF-DOQI). Clinical practice guidelines for bone metabolism and disease in chronic kidney disease. Am J Kidney Dis. 2003; 42(suppl. 3):1-201.

15. Hou SH, Zhao J, Ellman CF et al. Calcium and phosphorus fluxes during hemodialysis with low calcium dialysate. Am J Kidney Disease 1991; 18:217-24.

16. Zuchelli P, Santoro A. Inorganic phosphate removal during different dialitic procedures. Int J Art Organ. 1987; 10:173-8.

17. Chaveau P, Piognet JL, Kano T. Phosphate removal rate: A comparative study of five high-flux dialysers. Nephrol Dial Transplant. 1991; 6(supl2):114-15.

18. Cannata-Andia JB, Rodriguez-Garcia M. Hyperphosphatemia as a cardiovascular risk factor how to manage the problem. Nephrol Dial Transplant. 2002; 17(supl11):16-19.

19. Minutolo R, Belizzi V, Crofti M. Postdialytic rebound of serum phosphorus: pathogenesis and clinical insight. J Am Soc Nephrol. 2002; 13:1046-54. 
20. Uldall R, Ouwendyk M, Francoeur R et al. Slow nocturnal home hemodialysis at the Wellesley Hospital. Adv Ren Replace Ther. 1996; 3:133-6.

21. Kooistra MP, Vos J, Koomans HA et al. Daily home haemodialysis in The Netherlands: effects on metabolic control, haemodynamics, and quality of life. Nephrol Dial Transplant. 1998; 13:2853-60.

22. Mucsi I, Hercz G, Uldall R et al. Control of serum phosphate without any phosphate binders in patients treated with nocturnal hemodialysis. Kidney Int. 1998; 53:1399-404.
23. Lindsay RM, Alhejaili F, Nesrallah G et al. Calcium and phosphate balance with quotidian hemodialysis. Am J Kidney Dis. 2003; 42(Suppl 1):24-9.

24. Mizani M, Ayus JC. Control of severe hyperparathyroidism (SHPT) by short daily dialysis (SDHD) with concomitant use of high dose of vitamin D analog (paracalcitol). J Am Soc Nephrol. 2004; 15:736A. 